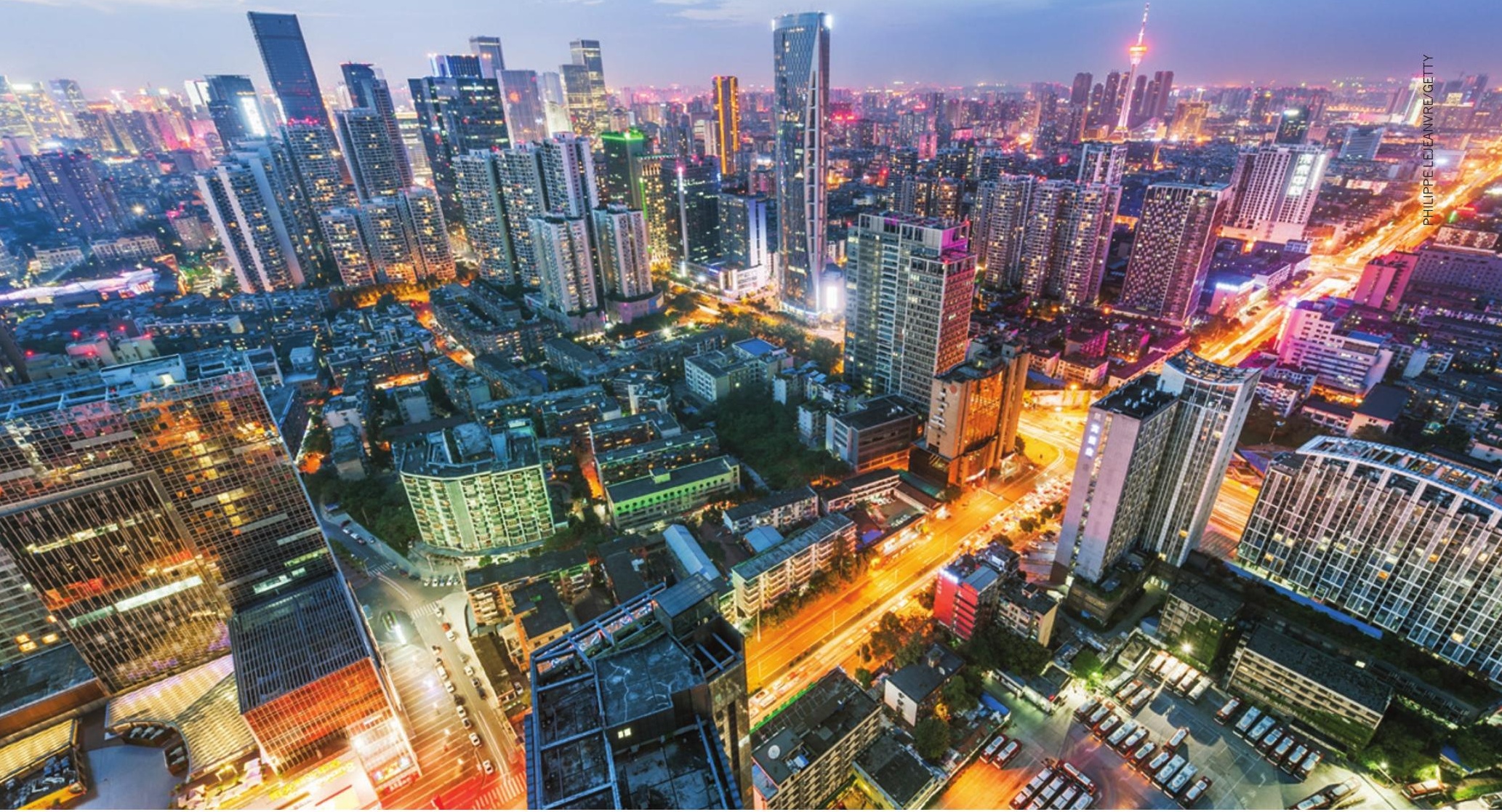

Chengdu's sparkling and fast-growing skyline is a shining testament to its transformation into a high-tech hub, which is home to almost 100 cutting-edge labs.

\title{
AT THE VERY HEART OF PROGRESS
}

The ambition driving China's astonishing progress in the output of high-quality science is particularly strong in some cities, whose growth far outstrips expectation.

\section{BY SARAH O'MEARA}

$\mathrm{W}$ hen neuroscientist Anna Wang Roe was looking two years ago for somewhere to set up a new stateof-the-art interdisciplinary neuroscience and technology institute, her search ended in the far eastern city of Hangzhou. "I looked at many top universities. But then I went to Zhejiang University [in Hangzhou] and it really stood out, even over some higher ranked Chinese institutions," she recalls.

Between 2012 and 2014, China's Nature Index WFC rose by $37 \%$. But several cities grew at an even faster rate - Hangzhou, Xian and Chengdu being some of the standout

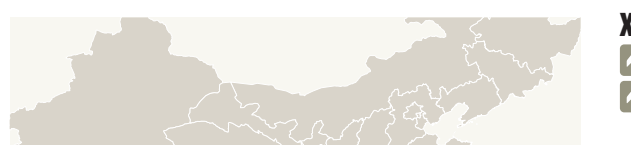

XI'ANo

CHENGDU HANGZHOUO examples (see 'Stellar performers').

The overall growth in publication output from these cities has largely been in chemistry (see 'Subject specialities'). Yet researchers working in these universities point to many factors, beyond expertise in a single discipline, for their success. Wang Roe, for instance, was so impressed by Hangzhou's atmosphere of energy, passion and collaboration that she approached the city's Zhejiang University, China's fifth largest Nature Index contributor in 2014, with her institute proposal. "At Zhejiang they have created a highly motivated research environment where people can share and explore freely. This doesn't always happen in China," she notes.

\section{XI'AN \\ 个 WFC rank China: 12 \\ A $A C: 309$}

Situated in China's northwestern Shanxi province, Xi'an shows the largest relative increase in WFC of the three cities, increasing by $142 \%$ from 2012 to 2014 (see 'Stellar performers'). WFC is a metric that apportions credit for each article according to the affiliations of the contributing authors.

Xi'an has a history of at least 3,000 years, more than a thousand of those as the capital of ancient Chinese dynasties. Since the early 1990s, when it emerged as the lead city of China's Western Development programme, Xi'an has promoted the value of tech-driven industry and established one of the earliest national high-tech development zones. The city is also home to a sophisticated national aviation base that was integral in manufacturing Shenzhou 6 , the craft that carried China's second manned space flight in 2005.

Between 2012 and 2014, the fast rise in the number of publications from Xian institutions featured in the Nature Index's 68 high-impact journals was led by Xi'an Jiaotong University. The largest subject increases were in chemistry and physical sciences.

Shan Zhiwei is deputy director of the university's State Key Laboratory for Mechanical Behavior of Materials, which contributed to almost $25 \%$ of Xi'an Jiaotong University's articles in the Nature Index in the three-year growth spurt. He believes the university's success is 


\section{STELLAR PERFORMERS}

The proportional increase of China's top 20 growing cities compared to their overall increase in WFC over three consecutive years between 2012 and 2014.

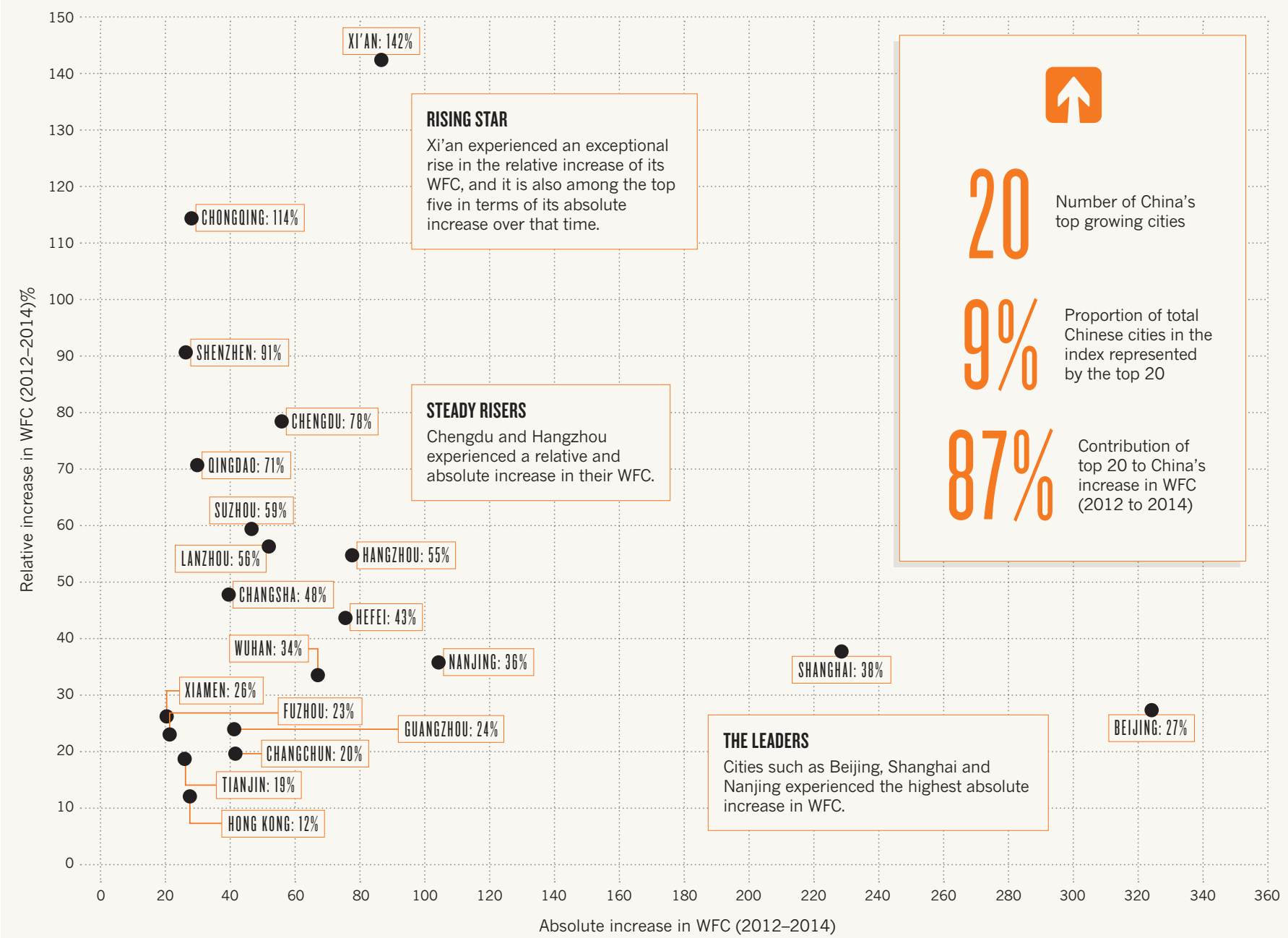

\section{SUBJECT SPECIALTIES}

While Xi'an, Chengdu and Hangshou experienced exceptional overall growth, it has been driven mostly by chemistry and physical sciences.

\section{Chemistry \\ Physical sciences \\ Life sciences \\ Earth \& environmental sciences}
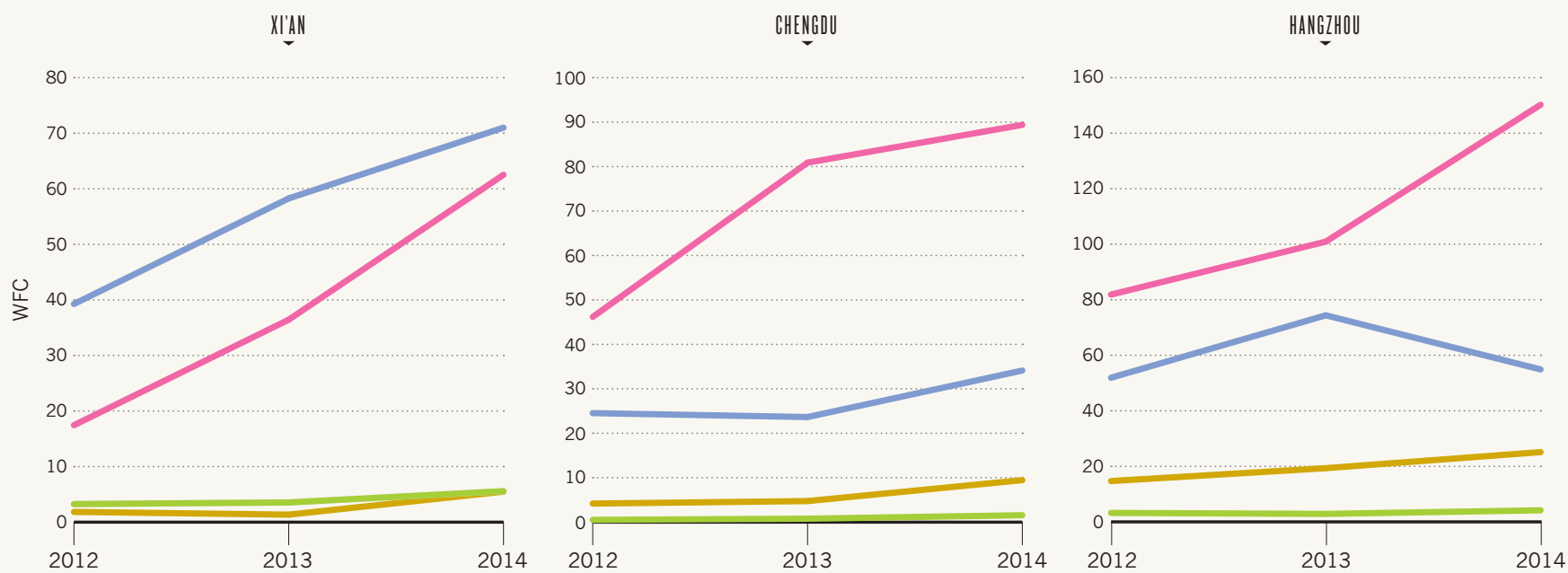
driven by government strategies to attract international science talent to China, combined with innovative recruitment policies. "Xian Jiaotong has developed a series "Anemphasis of local policies to on talent attract talents, includrecruitment ing offering attractive has been salaries, strong finanaccompanied cial support, and an by a willingness open and approachato embrace ble management style," new ways of explains Shan, who is new ways of also a director of the working." Center for Advancing from the Nanoscale (CAMP-nano),

Materials Performance

He adds that in the past five years, Xi'an Jiaotong has hired many foreign-born experts and enticed hundreds of Chinese-born professionals working abroad to return, bringing their education and experience. The recruitment drive has been accompanied by a willingness to embrace new approaches to work. "We drew on the strength of the new people," Shan says. "They have introduced new methods of training students, managing team members and handling instruments. In addition, the recruits have strong financial support. This combination has led to high efficiency of work and yielded good research outputs."

\section{CHENGDU \\ WFC rank China: 13 \\ A $A C: 287$}

Science and technology-driven development has transformed Chengdu into one of the world's fastest growing cities and led to a surge in high-quality research output. The WFC of Chengdu in the Nature Index increased by almost $80 \%$ between 2012 and 2014 (see 'Stellar performers').

The city has allocated enormous resources to create an environment where innovation thrives, starting in the laboratory. Chengdu now has 10 national key laboratories funded by China's central government, 30 labs established by branches of local government and 53 universities.

Between 2012 and 2014, the Nature Index contribution of the city's Sichuan University soared, particularly in chemistry and related disciplines. "Chengdu has become a hotbed for academic achievement," says Wei Yuquan, vice president of Sichuan University and director of the National Key Laboratory of Biotherapy, which contributed to articles in the Nature Index between 2012 and 2014. "Our multidisciplinary research centre has established an integrated technology chain for the discovery and development of innovative drug candidates in a single institute," he says.

Chengdu is the capital of the landlocked Sichuan province and has been growing rapidly since 2000, when China's central government began pouring money into poorer interior

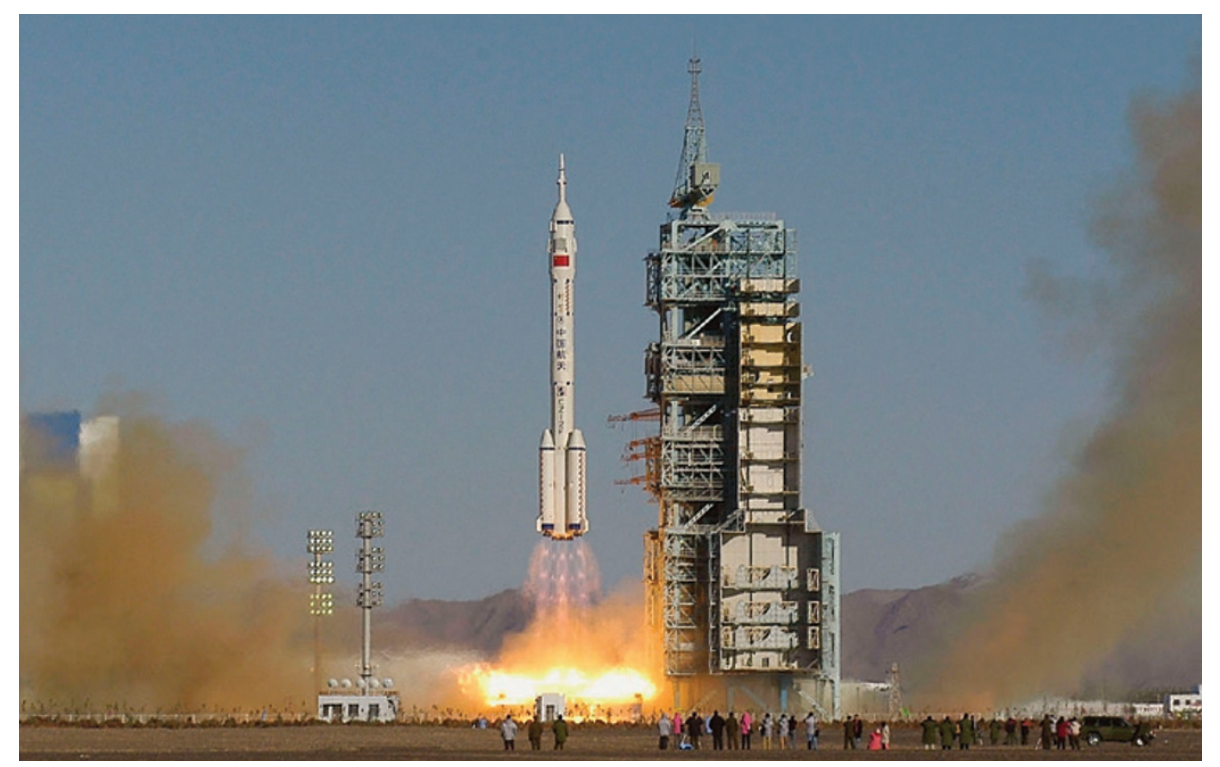

Xi'an's sophisticated aviation base was central to the manufacture of the spacecraft Shenzhou 6.

cities. Official policy has focused on turning the city into a high-tech hub, a role Chengdu was well positioned to fill. "Local government is establishing Chengdu as an area of innovation, and has set up many foundations to support research projects including basic research and to recruit talented researchers," Wei says.

Among them is Gong Qiyong, deputy dean of West China Medical School, Sichuan University in Chengdu. Ten years ago he resigned from a faculty position at the University of Liverpool in England to become the director of West China Hospital's Huaxi MR Research Center. "Now my group has been internationally recognized as one of the leading teams in psychiatric imaging," he says. "Recently we obtained a huge grant from the government to build the National Research Center of Translational Medicine."

\section{HANGZHOU \\ $\rightarrow$ WFC rank China: 8 ^ $A C: 458$}

Hangzhou is one of China's quintessential historic cities, but its rapidly increasing rate of high-impact research suggests its best years are yet to come. Hangzhou, where the Nature Index WFC jumped by 55\% from 2012 to 2014, has the largest absolute WFC of the three highest performing cities (see 'Stellar performers').

During the past decade, Hangzhou has become a hub for science-driven innovation from laboratory research to tech start-ups. It's home to the Alibaba Group, China's leading e-commerce service pro-

"There's huge energyin Hangzhou. They go for it with full force." promote technology transfer from the lab into business, and start-up funds for academics setting up companies at incubator sites.

Wang Yong is a professor at Zhejiang University's School of Materials Science and Engineering, which hosts a nationally-funded laboratory for silicon materials, and contributed to papers from the university in the Nature Index between 2012 and 2014. Wang is researching the catalytic mechanism of nanocrystals at nanoscale in order to develop high performance catalysts for future industry use. "The local government is rich and invests a large amount of money in universities," he explains. "There is good startup funding available, financial incentives for high-quality work, state-of-the-art facilities, and the opportunity to innovate and collaborate with industry."

Hangzhou also benefits from leaders whose clear vision was a big factor behind Wang Roe's decision two years ago to ask Zhejiang University for a US $\$ 25$ million grant to build her Interdisciplinary Institute of Neuroscience and Technology, of which she is now the director.

"The administration tells me the grant was the largest investment of any university in China on a single project," Wang Roe says.

The five-storey building with 20 labs and a large primate facility officially opened in October 2015. Academics came from all over the world for the opening ceremony and conference. "[They] were very impressed [and] amazed that this could be achieved in such a short time," Wang Roe says. "I looked at many high-level institutions in China for this project, but Zhejiang had it all; excellent engineering, optics, materials science, information sciences, neuroscience and medicine, and a collaborative environment.

"There's huge energy in Hangzhou. Once the administration decides on something, they go for it with full force with the long-term in mind. It makes you think differently, it really does." - 